\title{
ESR Mitgliedschaft
}

\section{Profitieren Sie als DRG-Mitglied von einer kostenlosen Mitglied- schaft in der European Society of Radiology (ESR)}

Wenn Sie Mitglied der Europäischen Röntgengesellschaft (European Society of Radiology, ESR) werden wollen, übernimmt die Deutsche Röntgengesellschaft die Mitgliedsgebühr für Ihre ESR-Mitgliedschaft.

\section{Ihre Vorteile}

Mitglieder der ESR erhalten einen kostenlosen Zugang zur Online-Version der Zeitschrift European Radiology und zu den übrigen Online-Angeboten der ESR. Darüber hinaus sind die Teilnahmegebühren für den European Congress of Radiology (ECR), der alljährlich im März in Wien stattfindet, für ESR-Mitglieder reduziert.

\section{ESR-Mitgliedschaft beantragen}

Da eine Mitgliedschaft in einem Verein persönlich beantragt werden muss, kann die DRG den Aufnahmeantrag nicht für Sie stellen. Wir bitten Sie daher, sich bei der ESR anzumelden. Den entsprechenden Link finden Sie auf unserer Homepage www.drg.de. Bitte beachten Sie, dass Sie den Preisnachlass für den Europäischen Röntgenkongress (ECR) nur erhalten, wenn Sie bis spätestens Ende August des Vorjahres den Aufnahmeantrag gestellt haben. Um die Daten aktuell zu halten, muss die Mitgliedschaft jedes Jahr erneuert werden. Den Link dazu finden Sie ebenso auf unserer Homepage www.drg. de. 